\title{
Preventing Postoperative Seroma formation in Abdominal wall Hernia by Intraoperative Hypertonic Saline Irrigation, early Report
}

\author{
Dudai Moshe ${ }^{1,2 *}$ and Ittah Gilboa Karen ${ }^{1}$ \\ ${ }^{1}$ Department of Surgery, MERAV Medical Center Bat-Yam, Israel \\ ${ }^{2}$ Hernia Excellence Tel-Aviv, Israel
}

Received: December 03, 2018; Published: January 08, 2019

*Corresponding author: Moshe Dudai MD FACS, Department of Surgery, MERAV Medical Center Bat-Yam, Israel

Abstract

Seroma formation is a frequent post-operative complication of many operations, mainly abdominal wall Hernias and reconstructive surgeries, where extensive dissection take place. It increases overall morbidity and can be challenging to manage. Drains, aspirations and sclerotherapy are established for treating postoperative seromas and increase the risk for infections. No study has yet to describe the use of intraoperative hypertonic saline irrigation as a preventive measure for seroma formation. The purpose of this report is to describe a novel intraoperative method of hypertonic saline irrigation to abdominal wall subcutaneous surgical cavity, which prevent seroma formation and enables a shorter drainage usage due to early drain removal. Thus, reducing infections and overall morbidity, shortening hospitalization period and decreasing the annoying inconveniency of repeated aspirations and drains insertion with significant cost saving.

Our experience is preventing abdominal wall seromas formation in seven patients undergone the Extended Endoscopic Hernia \& Linea Alba Reconstruction Glue surgery for Ventral Hernias and Rectus Muscles Separation. A wide endoscopic dissection of the anterior Rectus fascia is followed by mesh placing over the repaired Rectus muscles which is fused to the muscles with Fibrin Glue. A developed novel preventive method includes Intraoperative Irrigation of the cavity through two $7 \mathrm{~mm}$ Jackson-Pratt closed system drains with $20 \mathrm{cc}$ of $\mathrm{NaCl} 10 \%$, left in place for 10 minutes. We have excellent early results of seroma prevention, reduced secretions and drain removal within 20 hours. This method can be applied in other potential seroma formation surgeries. Further follow up will be needed.

Keywords: Intraoperative Hypertonic Saline Irrigation; Hypertonic Saline; Seroma Formation; Extended Endoscopic Hernia \& Linea Alba Reconstruction Glue; Rectus Muscles Separation; Ventral Hernia; Umbilical Hernia; Sclerosant; Diastasis Rectaii

Abbreviations: IHSI: Intraoperative Hypertonic Saline Irrigation; HS: Hypertonic Saline; SF: Seroma Formation; eEHLARglue: Extended Endoscopic Hernia \& Linea Alba Reconstruction Glue; RMS: Rectus Muscles Separation; VH: Ventral Hernia; UH: Umbilical Hernia; Sclerosant; Diastasis Rectaii

\section{Introduction}

Seroma formation (SF) is a common post-operative complication of many operations [1]. Extensive dissection area resulting in a big dead space predispose the accumulation of fluid and the formation of a postoperative seroma and is one of the greatest risk factors for its formation. The larger the surgical intervention, the more likely it is that seromas appear. Plastic and Reconstructive surgeons use techniques like extensive dissecting, development and reposition of myo/fascio/cutaneous flaps and harvesting tissues in order to reallocate them to another area in the body, often leaving a dead space behind them. Therefore, seromas are particularly common after reconstructive surgeries.

Postoperative seromas are seen after breast surgery and high seroma rates are reported. A post mastectomy seroma is reported to have an incidence of 3\% to more than $90 \%$ [2-4]. Prevalence of $2 \%-20 \%$ was reported in implant-based breast reconstructions.
After breast reconstruction using lipofilled latissimus dorsi flap, seroma required repeated drainage occurred in $10 \%$ of cases [5]. After breast augmentation, seroma is reported to occur in $2 \%$ of cases [6]. Liposuction, one of the most common procedures in the United States [7], includes leaving a large dead space, and postoperative seromas are reported to occur in $5 \%$ of the cases [8].

Big subcutaneous space formed during surgery of the abdominal wall, is also one of the most common sites for postoperative seroma. After a breast reconstruction using DIEP free flap, where fat and skin with their vasculature are harvested from the lower abdomen, micro surgically connected to vessels in the chest and repositioned instead of the former breast tissue, a prevalence of $2.8 \%-4 \%$ is reported for seroma formation in the abdominal wall [9]. Abdominoplasties are commonly performed by plastic surgeons as a part of body contouring surgeries after 
massive weight loss. The prevalence of seroma formation after abdominoplasty is ranging from $5 \%-43 \%$ [10].

Postoperative seromas can be seen after big hernia repairs at the Hernia location. Morales-Conde et al. [11] reported an incidence of $46 \%$ of seroma formation in 3 months follow up. Seroma can develop following laparoscopic inguinal hernia repair by extraperitoneal (TEP) and transabdominal approach (TAPP) in up to 37 and $18 \%$ of cases, respectively [12]. Wide subcutaneous dissection for closing big abdominal wall defect and Rectus muscles separation is also a ground for seroma formation due to large dead space development. Susmallian et al. [13] reported an incidence of $35 \%$ of seromas diagnosed clinically in patients undergone laparoscopic repair of incisional hernia. An Ultrasound assisted diagnosis demonstrated seroma in $100 \%$ of cases. Lund et al. reported postoperative seroma occurred in $22 \%$ of cases after laparoscopic ventral hernia repair [14]. Additionally, it has been shown that degree of lymphatic interruption, such as axillary or inguinal lymph node dissection, increases rate of seroma formation [15].

Complications of postoperative seroma vary from delayed wound healing, repeated seroma aspirations with the risk of infection, prolonged hospital stay, skin flap necrosis, patient discomfort, repeated visits to the outpatient clinic, delay in commencing adjuvant therapies when needed and higher surgical expenditures [16-18]. Seromas may be challenging to manage at times and may persist for several months or even years $[19,20]$ depending on the volume and duration of serous secretions. Conservative, non-invasive ways to manage seroma include application of pressure dressings [21].

Invasive procedures such as replacement of drains and repeated percutaneous aspiration are sometimes needed in order to achieve resolution [1,22] and are controversial [23]. While seromas can be a culture medium for bacteria and get infected [24] and reducing its size may prevent infections and increase resolution, the aspiration itself carried out under aseptic conditions carries a risk of infection. If a seroma does not resolve, it may be necessary to take the patient back to the operating room in order to place some form of closed-suction drain into the wound, resect the cavity lining or inject a sclerosant. However, this usually is not necessary in non-complicated cases and conservative management prevails [25].

The cost of longer hospitalization, repeated outpatient visits and a second surgery is high for both the patient and the health system. It has been shown that reducing the length of hospital stay is the most expeditious way to reduce surgical costs [26]. It has also been proven that postoperative seroma, although regarded by many surgeons as an inevitable nuisance rather than a true complication, can lead to significant morbidity including prolongation of hospital stay $[27,28]$.

A multifactorial process is responsible for the formation of seromas. Blood and lymphatic vessels and an inflammatory process both contribute to accumulation of inflammatory exudate, lymph and plasma in a space, created either by surgery or by trauma $[1,22,25,29]$. Shear forces maintain the dead space thus preventing adhesion of the tissue surfaces. These fluid collections will form pseudocysts as the cavity becomes lined by fibrous tissue with no proper epithelium [29]. Preventing seromas can start by identifying and minimizing risk factors such as large dead space, elevated BMI, electrocautery, and time-controlled drain removal $[1,22]$. However, seromas may and do continue to form. One of the methods to treat seromas is injection of a sclerosant [25].

Sclerotherapy involves filling the seroma cavity with an irritating substance, which induces a fibrotic response needed to seal the dead space. Several sclerosants stimulate fibrous union of the tissue surfaces by inducing an inflammatory reaction which causes fibrosis and closure of the pseudocyst [30]. Others do it through destruction of mesothelial cells lining as well as by inhibiting fibrinolysis and the induction of fibroblast growth factors. Some sclerosants, like fibrin glue, are not based on an inflammatory response and contains fibrinogen, factor XIII, thrombin, and calcium to stimulate the final stage of the clotting cascade [31].

Different sclerotherapies were reported; Talc, which is mainly known to address pleural effusion and obtain pleurodesis, can be used as a sclerosant in seromas in different anatomic sites, including abdominal wall seromas. It is applied as a dry powder, a slurry with or without local anesthetic or as an aerosol [32-37]. Antibiotics like Tetracycline and Erythromycin were reported as the primary sclerosants to treat seromas in the trunk and the lower limbs [31,38-41]. Ethanol was also suggested as a sclerosant in seroma managing, used for different durations, from 10 minutes to 6 periods of 90 minutes $[30,42,43]$.

Additionally, Polidocanol solution or foam for sclerotherapy was reported [29,44]. Moritz et al. treated lower extremity seromas after varicose vein surgery by applying Polidocanol foam to seroma cavities and compression bandaging. Fasching and Sinzig reported in a case report the use of sclerosing agent OK-432, a mixture of a low-virulence strain of Streptococcus pyogenes incubated with benzylpenicillin potassium, to treat a sacral seroma successfully [45]. Berkoff et al. reported using fibrin glue to treat a seroma of the knee in 2 weeks with no complications [25]. Finally, a combination therapy was reported by Throckmorton et al. who treated 18 mastectomy site seromas in 16 patients [42].

Sclerotherapy was performed by instilling 95\% ethanol or dilute povidone-iodine for 20 to 30 minutes, with drains placed for postoperative management. Several patients received ethanol with doxycycline during repeat treatments. The use of Hypertonic Saline was only sporadically reported in the past for the treatment of fluid collections. Hypertonic Saline irrigation was reported as a treatment to hepatic hydatid cyst, the larval stage of the dog tape worm Echinococcus Granuloses, as early as in 1984 by Gage and Viviane [46]. Hypertonic Saline was also mentioned as sclerosing agent for reticular and telangiectatic leg veins [47]. For the 
treatment of a postoperative seromas, we were able to detect in the literature only one citation as a single experience in a letter to the editor in 2003 by Gruver [48].

Preventive measures for seroma formation can be divided to surgical and non-surgical and their purpose is to reduce the surgically formed dead space. Non-surgical methods include preventing movement between the layers of the dead space by avoiding or keeping certain positions, such as semi-recumbent in abdominoplasty. External pressure is thought to reduce the tendency of the fluid to leak out of vessels so a pressure dressing or an abdominal binder are used for several weeks postoperatively. Surgical methods to prevent seroma formation include techniques like quilting sutures [49], meticulous control of bleeding, sealing agents, like a collagen sponge coated with human coagulation factors [50], and the most traditional method, negative pressure using drains [22].

Recently, drains are falling out of favor due to evidence that support their use is limited and conflicting [51]. Prolonged drain use was associated with postoperative infection [52]. A systematic review evaluated the association of surgical site infection (SSI) with routine post-operative closed system drainage have yielded conflicting results. A few studies suggested an increased risk of SSI associated with drain placement but were usually associated with open drainage. They recommend judicious use and prompt, timely removal of closed system drainage [53]. No report in the literature was found for using intraoperative Hypertonic Saline or other sclerosant as a preventive measure for SF or for early drain removal.

The purpose of this report is to describe our developed novel method of Intraoperative Hypertonic Saline Irrigation (IHSI) to surgical cavity, which reduces SF rate, decreases drain secretions and enables a shorter drainage time due to early drain removal. As mention above, there is high prevalence rate in very commonly performed surgeries for SF leading to high risk of secondary complications like infections, annoying challenging management and treatment and finally high cost for both patient and heath care system due to longer hospitalization, repeated outpatient visits and potentially another surgery. All contribute to the rational of developing a new preventive method for postoperative SF.

\section{Materials and Methods}

Our experience is with preventing abdominal wall SF after the Extended Endoscopic Hernia \& Linea Alba Reconstruction Glue surgery (eEHLARglue) for Ventral Hernia (VH) and Rectus Muscles Separation (RMS) [54,55]. This surgery combines wide Anterior Rectus Fascia dissection and therefore holds a high risk for seroma formation. An Endoscopic dissection of the subcutaneous fat tissue from the Anterior Rectus Fascia is performed at the beginning of the surgery. The Endoscopic penetrating is with tree trocars from the supra-pubic line dissecting up to the Xiphoid, laterally $7 \mathrm{~cm}$ away from the Rectus muscles separation line. Any Hernia sac is dissected, and the content reduce back to the abdominal cavity (Figures 1-3).

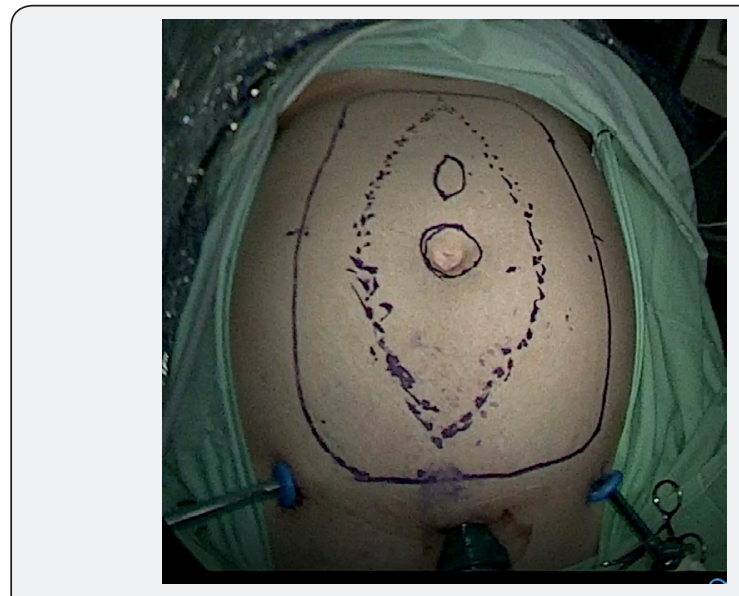

Figure 1: External mark for any hernias, the rectus muscle separation and $7 \mathrm{~cm}$ away from the Rectus muscles separation to set the dissection limits and trocar insertion site.

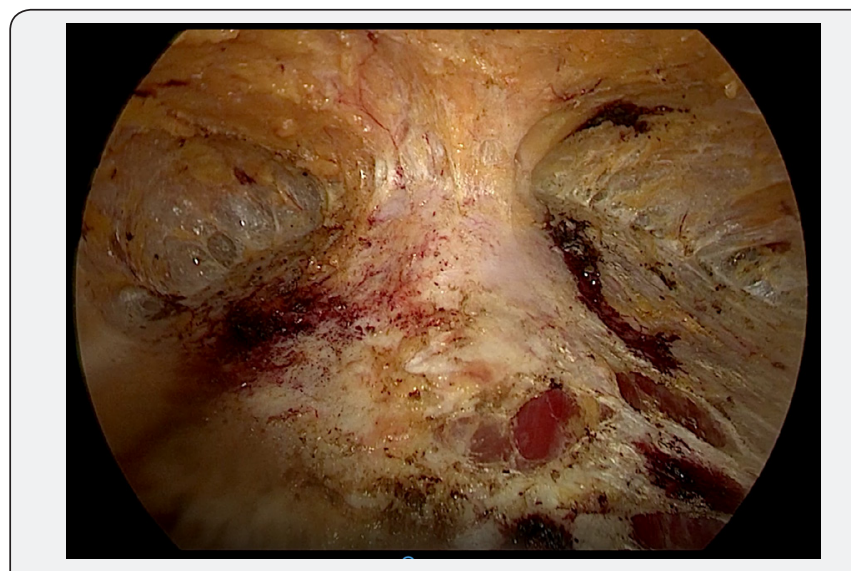

Figure 2: Hernia sac is dissected.

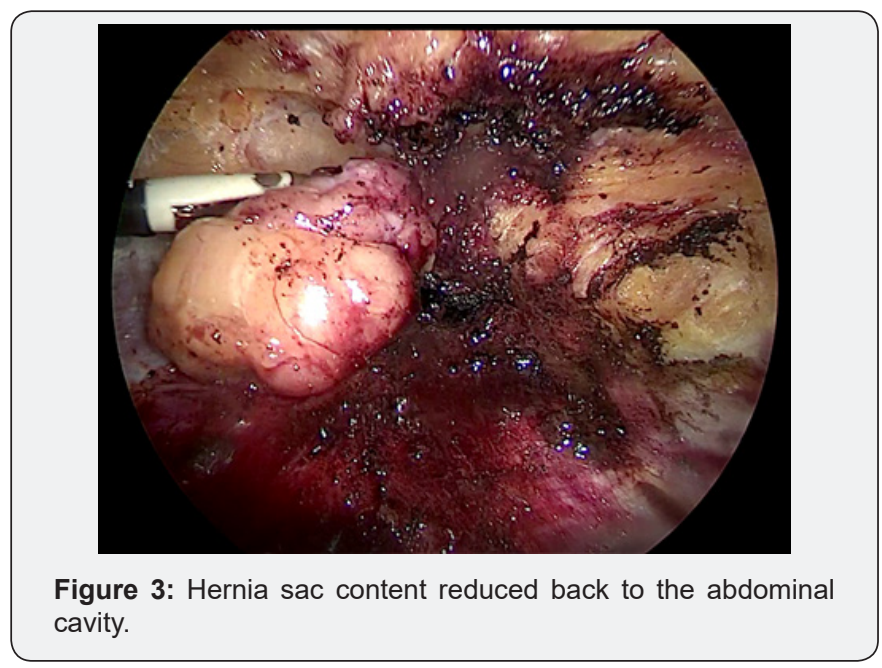

Relaxing Incision of the Rectus Fascia are performed longitudinally in the lateral aspect. The Rectus Separation is closed by two rows of $\mathrm{V}$ - lock suture plications: $1^{\text {st }}$ plicate the loos Linea Alba Figure 4, and $2^{\text {nd }}$ plicate the Anterior Rectus Facia Figure 5; a New Linea Alba is reconstructed Figure 6. A light Prolen Soft Mesh $30 \mathrm{X} 15 \mathrm{cn}$ is placed over the repaired Rectus Muscles and irrigation with 4+4 cc Fibrin Glue all over the mesh area is performed 


\section{Open Access Journal of Surgery}

for achieving immediate homogeneous fusion of the mesh surface to the muscles and hemostasis Figure 7. Two $7 \mathrm{~mm}$ Jackson-Pratt closed system drains are inserted through the bottom $5 \mathrm{~mm}$ trocars skin port cut (Figure 8).

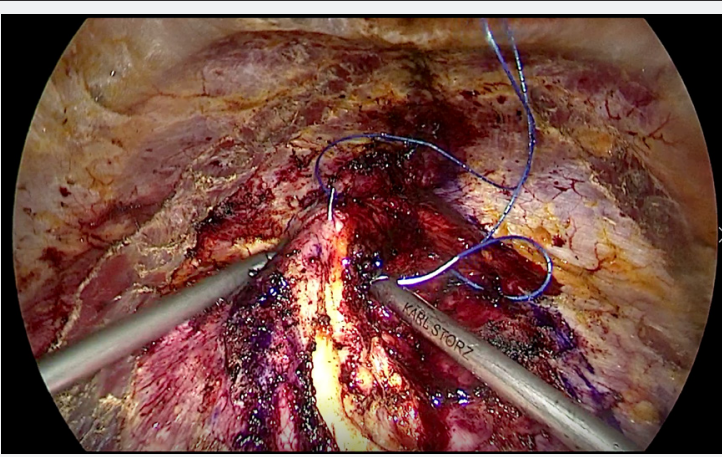

Figure 4: The Rectus separation is closed by two rows V- lock suture plications $-1^{\text {st }}$ plication of the loos Linea Alba.

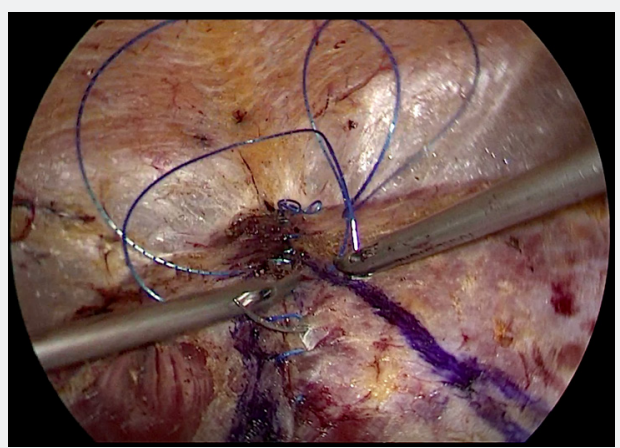

Figure 5: $2^{\text {nd }}$ plication of the anterior Rectus facia.
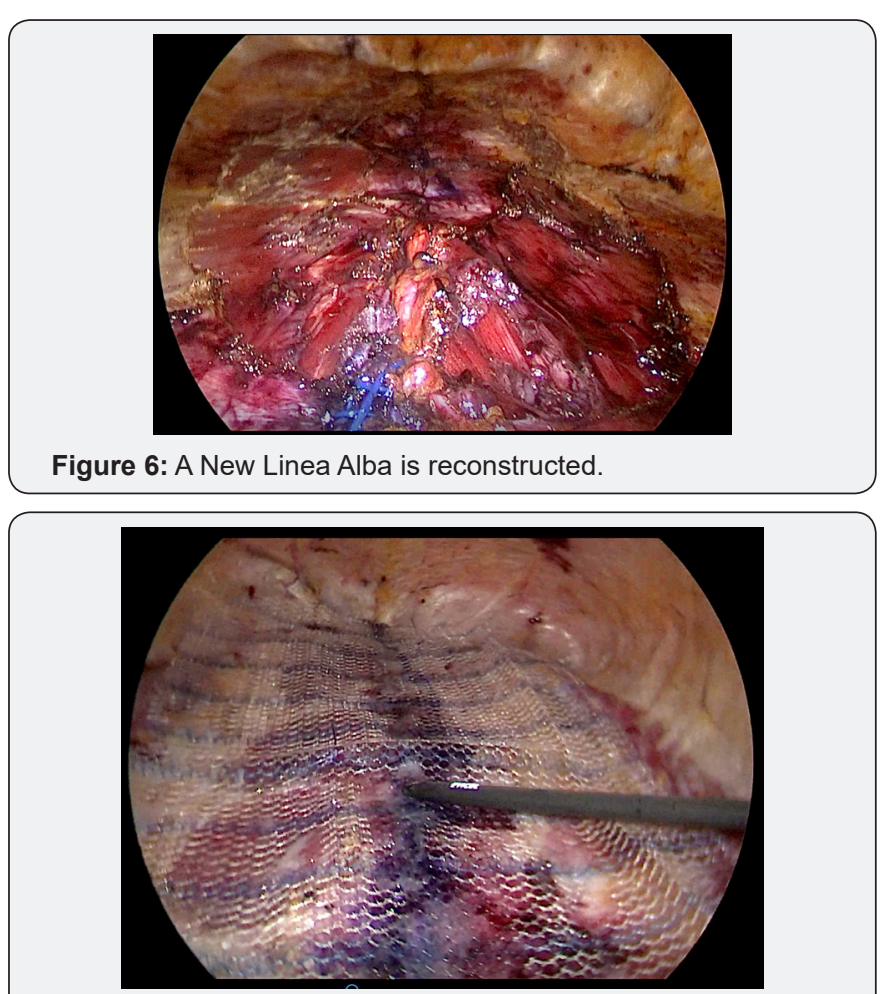

Figure 7: A light Prolen Soft Mesh is placed over the repaired Rectus muscles and Irrigation with $4+4$ cc Fibrin Glue all over the mesh area for achieving immediate mesh fusing to the muscles.

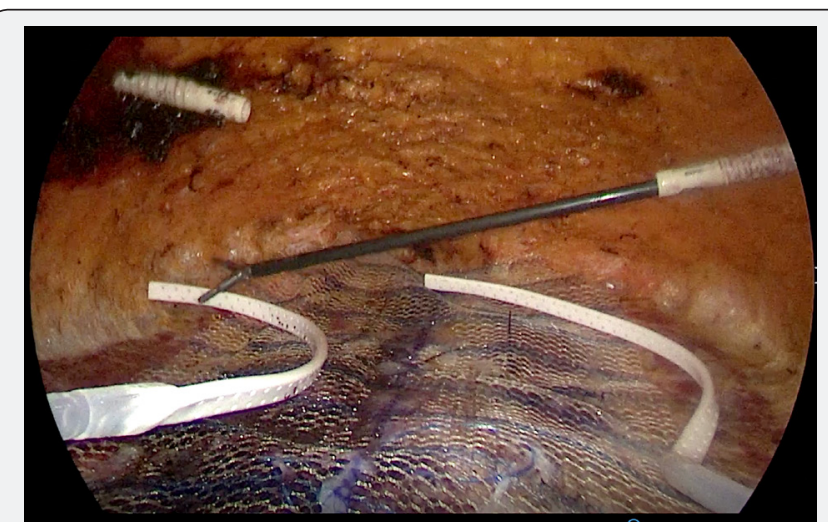

Figure 8: Two $7 \mathrm{~mm}$ Jackson-Pratt closed system drains are inserted through the bottom $5 \mathrm{~mm}$ trocars skin port cut.

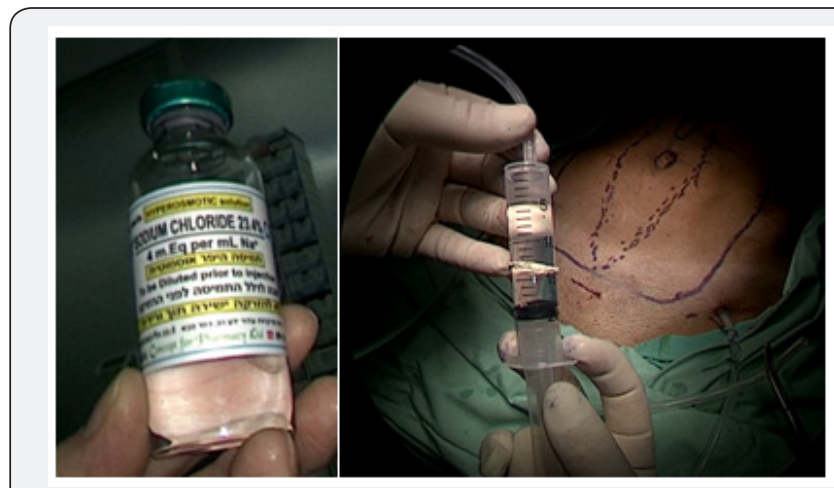

Figure 9: Irrigating the developed cavity with Hypertonic 10\% $\mathrm{NaCl}$.

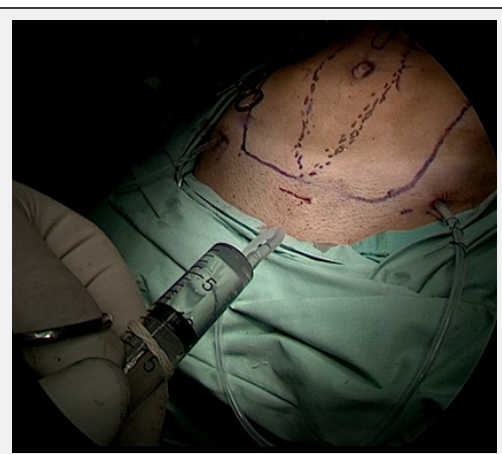

Figure 10: Through each of the two drains $10 \mathrm{cc}$ (total 20cc) of $\mathrm{NaCl} 10 \%$ are injected.

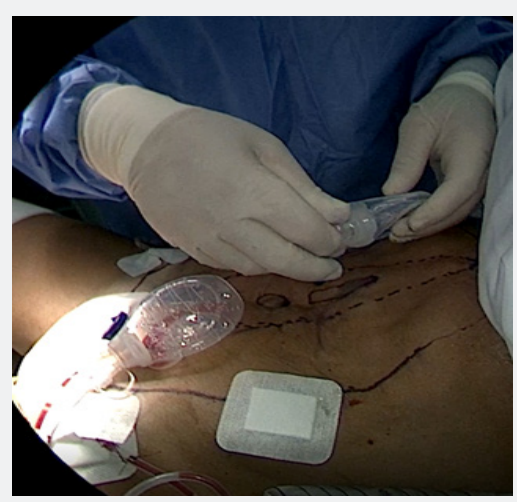

Figure 11: Hypertonic Saline is left in place for 10 minutes before connecting the vacuum chamber. 
Our novel IHSI method includes: At the end of the surgery, irrigating the developed cavity with Hypertonic $10 \% \mathrm{NaCl}$ Figure 9. Through each of the two drains Figure 10, $10 \mathrm{cc}$ of NaCl $10 \%$ (Total 20cc) are injected and left in place for 10 minutes before connecting the vacuum chamber Figure 11. Abdominal binders are wrapped in the OR table and used for 3 months postoperatively.

\section{Results and Discussion}

We encountered two cases of big SF post eEHLARglue surgery. In both cases patients were overweigh men with extensive RMS combined with Umbilical Hernia, in one patient it was a recurrent Umbilical Hernia. Both cases of postoperative seromas were treated with extensive drainage and we decided to complete it with irrigation through the inserted drain with Hypertonic Saline $10 \%$. The results were successful, and that lead us to think one step ahead to find a preventive method. We developed and applied the novel preventive method of IHSI to a surgical cavity in our eEHLARglue surgery for VH and RMS. We applied the IHSI method on seven patients, five women and two men, treated for different reasons (Table 1).

Table 1: Patients undergone eEHLAR glue surgery and IHSI.

\begin{tabular}{|c|c|c|c|}
\hline Gender & Age & RMS Size & Hernia Type \\
\hline Female & 51 & $24 \times 6$ & Umbilical + Recurrent Epigastric \\
\hline Female & 44 & $22 \times 7$ & Umbilical + Epigastric \\
\hline Female & 36 & $20 \times 9$ & Umbilical + Epigastric \\
\hline Female & 39 & $16 \times 4$ & Umbilical \\
\hline Female & 33 & $22 \times 9$ & Umbilical + Large Epigastric \\
\hline Male & 54 & $22 \times 5$ & Umbilical + Recurrent Epigastric \\
\hline Male & 34 & $27 \times 5$ & Umbilical \\
\hline
\end{tabular}

We had excellent early results of seroma prevention, and in three months follow up, no evidence of SF was found in any of the patients. Drain secretions were clear serosanguineous and were reduced in volume right from the very beginning, approaching to a secretion rate of $20 \mathrm{cc}$ in 10 hours. Drains were removed 2024 hours postoperatively in all patients. IHSI reduces seroma formation rate, decreases drain secretions and enables an early drain removal. Postoperative seromas are common, challenging to manage and hold a risk for further complications to repeated aspirations and additional surgery. IHSI can thus reduce overall morbidity and costs due to shorter hospitalization period and less outpatient visits. There is no effective preventing method of SF in the literature for this common complication, and a real solution is required. This IHSI method can be the answer and can be applied in other potential SF surgeries.

\section{Conclusion}

IHSI to a surgical cavity addresses the prevention of one of the most common and annoying surgical complication, postoperative SF. It reduces SF rate, decreases drain secretions and enables an early drain removal as we demonstrate in our early cases of eEHLARglue. Thus, reducing overall morbidity and hospitalization period and saving costs and inconveniency due to repeated outpatient visits and aspiration or additional surgery. IHSI can be applied in other potential SF surgeries. Additionally, the majority of SF are developed in the early postoperative period, and further follow up will be needed.

\section{References}

1. Shermak MA, Rotellini-Coltvet LA, Chang D (2008) Seroma development following body contouring surgery for massive weight loss: patient risk factors and treatment strategies. Plast Reconstr Surg 122(1): 280-288.

2. Carless PA, Henry DA (2006) Systematic review and meta-analysis of the use of fibrin sealant to prevent seroma formation after breast cancer surgery. Br J Surg 93(7): 810-819.

3. van Bastelaar J, Granzier R, van Roozendaal LM, Beets G, Dirksen CD, et al. (2018) A multi-center, double blind randomized controlled trial evaluating flap fixation after mastectomy using sutures or tissue glue versus conventional closure: protocol for the Seroma reduction After Mastectomy (SAM) trial. BMC Cancer 18(1): 830.

4. Woodworth PA, McBoyle MF, Helmer SD, Beamer RL (2000) Seroma formation after breast cancer surgery; incidence and predicting factors. Am Surg 66(5): 444-450.

5. Johns N, Fairbairn N, Trail M, Ewing A, Yong L, et al. (2018) Autologous breast reconstruction using the immediately lipofilled extended latissimus dorsi flap. J Plast Reconstr Aesthet Surg 71(2): 201-208.

6. Sforza M, Husein R, Atkinson C, Zaccheddu R (2017) Unraveling Factors Influencing early Seroma Formation in Breast Augmentation Surgery. Aesthet Surg J 37(3): 301-307.

7. (2016) Cosmetic surgery national data bank statistics. Aesthet Surg J 36(Suppl 1): 1-29.

8. Triana L, Triana C, Barbato C, Zambrano M (2009) Liposuction: 25 years of experience in 26,259 patients using different devices. Aesthet Surg J 29(6): 509-512.

9. Thacoor A, Kanapathy M, Torres-Grau J, Chana J (2018) Deep inferior epigastric perforator (DIEP) flap: Impact of drain free donor abdominal site on long term patient outcomes and duration of inpatient stay. J Plast Reconstr Aesthet Surg 71(8): 1103-1107.

10. Seretis K, Goulis D, Demiri EC, Lykoudis EG (2017) Prevention of Seroma Formation Following Abdominoplasty: A Systematic Review and Meta-Analysis. Aesthet Surg J 37(3): 316-323.

11. Morales Conde S, Suarez Artacho G, Socas Macias M, Barranco Moreno A (2015) Retroprosthetic seroma after laparoscopic ventral hernia repair: incidence, risk factors and clinical significance. Hernia 19(6): 943-947.

12. Krishna A, Misra MC, Bansal VK, Kumar S, Rajeshwari S, et al. (2012) Laparoscopic inguinal hernia repair: transabdominal preperitoneal (TAPP) versus totally extraperitoneal (TEP) approach: a prospective randomized controlled trial. Surg Endosc 26(3): 639-649.

13. Susmallian S, Gewurtz G, Ezri T, Charuzi I (2001) Seroma after laparoscopic repair of hernia with PTFE patch: is it really a complication? Hernia 5(3): 139-141.

14. Lund S, Farley D (2018) A decade of experience with laparoscopic ventral hernia repairs. Am J Surg S0002-9610(18)30926-7.

15. Petrek JA, Peters MM, Nori S, Knauer C, Kinne DW, et al. (1990) Axillary lymphadenectomy. A prospective randomized trial of 13 factors influencing drainage including early or delayed arm mobilization. Arch Surg 125(3): 378-382.

16. Kumar S, Lal B, Misra MC (1995) Post-mastectomy seroma: a new look into the aetiology of an old problem. J R Coll Surg Edinb 40(5): 292294. 
17. Tadych K, Donegan WL (1987) Postmastectomy seromas and wound drainage. Surg Gynecol Obstet 165(6):483-487.

18. Almond LM, Khodaverdi L, Kumar B, Coveney EC (2010) Flap anchoring following primary breast cancer surgery facilitates early hospital discharge and reduces costs. Breast Care (Basel) 5(2): 97-101.

19. Sood A, Kotamarti VS, Therattil PJ, Lee ES (2017) Sclerotherapy for the Management of Seromas: A Systematic Review. Eplasty 17:e25.

20. Kuthe A (2016) Successful treatment of a chronic abdominal wall seroma with the polysaccharide 4 DryField $®$ PH-A case report. Int J Surg Case Rep 27: 48-50.

21. Kontos M, Petrou A, Prassas E, Tsigris C, Roy P, et al. (2008) Pressure dressing in breast surgery: is this the solution for seroma formation? J BUON 13(1): 65-67.

22. Janis JE, Khansa L, Khansa I (2016) Strategies for postoperative seroma prevention: a systematic review. Plast Reconstr Surg 138(1): 240-252.

23. Depalma M (2011) Ispine: Evidence-Based Interventional Spine Care. Demos Medical Publishing pp: 245. ISBN 978-1-935281-93-1.

24. Jordan SW, Khavanin N, Kim JY (2016) Seroma in Prosthetic Breast Reconstruction. Plast Reconstr Surg 137(4): 1104-1116.

25. Berkoff DJ, Kanaan M, Kamath G (2013) Fibrin glue as a non-invasive outpatient treatment for post-arthroscopic knee seromas. Knee Surg Sports Traumatol Arthrosc 21(8): 1922-1924.

26. Tartter PI, Beck G, Fuchs K (1994) Determinants of hospital stay after modified radical mastectomy. Am J Surg 168(4): 320-324.

27. Aitken D, Minton J (1983) Complications associated with mastectomy. Surg Clin North Am 63(6): 1331-1352.

28. Chilson TR, Chan FD, Lonser RR, Wu TM, Aitken DR (1992) Seroma prevention after modified radical mastectomy. Am Surg 58(12): 750 754.

29. Moritz RK, Reich Schupke S, Altmeyer P, Stucker M (2013) Polidocanol foam sclerotherapy of persisting postoperative seromas after varicose vein surgery: a series of six cases. Phlebology 28(7): 341-346.

30. Penaud A, Quignon R, Danin A, Bahe L, Zakine G (2011) Alcohol sclerodhesis: an innovative treatment for chronic Morel-Lavallée lesions. J Plast Reconstr Aesthet Surg 64(10): e262-264.

31. Bansal A, Bhatia N, Singh A, Singh AK (2013) Doxycycline sclerodesis as a treatment option for persistent Morel-Lavallée lesions. Injury 44(1): 66-69.

32. Saeb-Parsy K, Athanassoglou V, Benson JR (2006) Talc seromadesis: a novel technique for the treatment of chronic seromas following breast surgery. Breast J 12(5): 502-504.

33. Luria S, Applbaum Y, Weil Y, Liebergall M, Peyser A (2016) Talc sclerodhesis of persistent Morel-Lavallée lesions (posttraumatic pseudocysts): case report of 4 patients. J Orthop Trauma 20(6): 435438.

34. Holthouse DJ, Chleboun JO (2001) Talc serodesis-report of four cases. J R Coll Surg Edinb 46(4): 244-245.

35. Lehr SC, Schuricht AL (2001) A minimally invasive approach for treating postoperative seromas after incisional hernia repair. JSLS 5(3): 267-271.

36. Catsman CJ, Beek MA, Rijken AM (2016) Talc seromadesis in patients with chronic seroma formation after breast surgery. SpringerPlus 5:3.

37. Metcalfe D, Sinha S, Sadek N, Ho AL, Karthikesalingam A, et al. (2013) Successful use of talc sclerodesis to control a persistent high-output groin seroma following endovascular abdominal aortic aneurysm repair. Ann Vasc Surg 27(6): 801.e9-e12.
38. Tejwani SG, Cohen SB, Bradley JP (2007) Management of MorelLavallee lesion of the knee: twenty-seven cases in the national football league. Am J Sports Med 35(7): 1162-1167.

39. Singh A, Anand A, Mittal S, Sonkar AA (2016) Morel-Lavallee seroma (post-traumatic pseudocyst) of back: a rarity with management conundrum. BMJ Case Rep pii: bcr2016216122.

40. Widgerow AD, Song C, Ritz M, Potgieter E (1997) Wound modulation via sclerotherapy and tissue adhesion. Observations and discussion. S Afr J Surg 35(2): 88-92.

41. Salgado M, Fernandez F, Aviles C, Cordova C (2016) Erythromycin seromadesis in orthopedic surgery. J Orthop Case Rep 6(2): 92-94.

42. Throckmorton AD, Askegard-Giesmann J, Hoskin TL, Bjarnason $\mathrm{H}$, Donohue JH, et al. (2008) Sclerotherapy for the treatment of postmastectomy seroma. Am J Surg 196: 541-544.

43. Isaacson AJ, Stavas JM (2013) Image-guided drainage and sclerodesis of a Morel-Lavallee lesion. J Vasc Interv Radiol 24(4): 605-606.

44. Laverson S (1999) Polidocanol for refractory seroma. Plast Reconstr Surg 104(4): 1212 .

45. Fasching G, Sinzig M (2007) OK-432 as a sclerosing agent to treat wound-healing impairment. Eur J Pediatr Surg 17(6): 431-432.

46. Gage TP, Vivian G (1984) Hypernatremia after hypertonic saline irrigation of a hepatic hydatid cyst. Ann Intern Med 101(3): 405.

47. Peterson JD, Goldman MP, Weiss RA, Duffy DM, Fabi SG, et al. (2012) Treatment of reticular and telangiectatic leg veins: double-blind, prospective comparative trial of polidocanol and hypertonic saline. Dermatol Surg 38(8): 1322-1330.

48. Gruver DI (2003) Hypertonic saline for treatment of seroma. Plast Reconstr Surg 112(3): 934.

49. Lee KT, Mun GH (2015) Fibrin Sealants and Quilting Suture for Prevention of Seroma Formation Following Latissimus Dorsi Muscle Harvest: A Systematic Review and Meta-analysis. Aesthetic Plast Surg 39(3): 399-409.

50.Piñero-Madrona A, Castellanos-Escrig G, Abrisqueta-Carrión J, Canteras-Jordana M (2016) Prospective randomized controlled study to assess the value of a hemostatic and sealing agent for preventing seroma after axillary lymphadenectomy. J Surg Oncol 114(4): 423-437.

51. Plymale MA, Harris JW, Davenport DL, Smith N, Levy S, et al. (2016) Abdominal Wall Reconstruction: The Uncertainty of the Impact of Drain Duration upon Outcomes. Am Surg 82(3): 207-211.

52. Hanna KR, Tilt A, Holland M, Colen D, Bowen B, et al. (2016) Reducing Infectious Complications in Implant Based Breast Reconstruction: Impact of Early Expansion and Prolonged Drain Use. Ann Plast Surg 76 (Suppl 4): S312-315.

53. Reiffel AJ, Barie PS, Spector JA (2013) A Multi-Disciplinary Review of the Potential Association between Closed-Suction Drains and Surgical Site Infection. Surg Infect (Larchmt) 14(3): 244-269.

54. Dudai M (2017) Endoscopic-Assisted Linea Alba Reconstruction (ELAR)-New technique for All Ventral Hernias in combination with Diastasis Rectaii-Abdominal Muscles Separation. The Biannual congress of The Israel Surgical Society, Kfar Blum, Israel.

55. Dudai M (2018) Extended Endoscopic Linea Alba Reconstruction Glue (eELARG)-New technique for Ventral Hernias in combination with Diastasis Recti-Abdominal Muscles Separation. Hernia 22(Suppl 1): S185. 


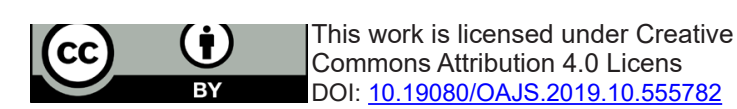

\section{Your next submission with Juniper Publishers will reach you the below assets}

- Quality Editorial service

- Swift Peer Review

- Reprints availability

- E-prints Service

- Manuscript Podcast for convenient understanding

- Global attainment for your research

- Manuscript accessibility in different formats

( Pdf, E-pub, Full Text, Audio)

- Unceasing customer service

Track the below URL for one-step submission https://juniperpublishers.com/online-submission.php 